\title{
PENENTUAN PEMBERIAN BONUS KARYAWAN PADA PERUSAHAAN DENGAN MENGGUNAKAN METODE TOPSIS
}

\author{
Johny Chandra, Santy Sipahutar, Oloan Sihombing* \\ Program Studi Sistem Informasi Fakultas Teknologi dan Ilmu Komputer Universitas Prima Indonesia \\ E-mail: *oloansihombing007@gmail.com
}

\begin{abstract}
ABSTRAK - Sumber daya manusia merupakan sumber daya yang memiliki akal, perasaan, keinginan, kemampuan, keterampilan, pengetahuan, dorongan, daya, dan karya. Salah satu cara pimpinan perusahaan untuk memotivasi para karyawan yang memiliki kemampuan dan semangat kerja yang tinggi dalam melakukan pekerjaannya adalah dengan memberikan penghargaan berupa bonus kepada karyawan sesuai dengan prestasi kerja yang dihasilkan. Bonus bisa menjadi salah satu pendorong karyawan menunjukkan kinerja lebih baik. PT. Shell merupakan perusahaan yang bergerak dalam bidang bidang pengolahan dan eksplorasi minyak dan gas biasanya juga memberikan bonus atas prestasi kinerja karyawan. Tetapi, proses pemberian bonus tahunan karyawan pada PT. Shell masih dilakukan secara manual, memerlukan waktu yang lama, serta kriteria yang digunakan dalam penilaian hanya berdasarkan kriteria absensi dan penilaian karyawan. Untuk itu, peneliti merancang sebuah sistem pendukung keputusan yang diharapkan mampu menyelesaikan masalah yang dihadapi. Perancangan sistem pendukung keputusan ini dibangun dengan menggunakan bahasa pemrograman Visual Studio 2010 dan SQL Server 2008, serta metode yang digunakan adalah metode TOPSIS. TOPSIS akan membantu proses perhitungan dalam pengambilan keputusan terhadap alternatif berdasarkan jarak terhadap solusi ideal positif dan jarak terhadap solusi ideal negatif dengan mengambil kedekatan relatif terhadap solusi ideal positif. Sistem pendukung keputusan menggunakan metode TOPSIS ini dapat memudahkan perusahaan dalam menentukan karyawan yang berhak mendapatkan bonus tahunan.
\end{abstract}

Kata Kunci: Sistem Pendukung Keputusan, Pemberian Bonus Karyawan dan Metode TOPSIS

\section{PENDAHULUAN}

Dalam setiap perusahaan, instansi, organisasi atau badan usaha akan memberikan gaji sebagai kompensasi dari kerja seorang karyawan. Perusahaan memberikan bonus disamping gaji pokok untuk meningkat kinerja dan produktifitas kerja seorang karyawan.Dalam hal ini seorang karyawan yang menerima bonus tersebut harus memenuhi beberapa kriteria tertentu yang berhubungan dengan kedisiplinan, kinerja, dan produktifitas sesuai yang ditentukan oleh suatu perusahaan [1].

PT. Shell adalah sebuah perusahaan yang bergerak dalam bidang pengolahan dan eksplorasi minyak dan gas, dimana setiap akhir tahun memberikanpenghargaankepadakaryawanberupa pemberian bonus tahunan.Proses pemberian bonus pada perusahaan dilakukandenganpenghitungan yang bersifat konvensional denganmenggunakan beberapa kriteria seperti absensi, penilaian karyawan, masa kerja dan loyalitas.Namun, dalam prakteknya sering terjadi keluhan dari karyawan dikarena bonus yang diberikan perusahaan tidak sesuai dengan kinerjanya.Untuk ituperlu dilakukan pengembangan sistem pemberian bonus berbasis komputer, sehingga pengolahan data dapat dilakukan dengan cepat, akurat dan dapat dipertanggung jawabkan.

Dalam permasalah di atas, maka dibangun suatu sistem informasi dalam penentuanpemberian bonus karyawan yang dirancang menggunakan metode Techinique for Order Preference by Similarity to Ideal Solution (TOPSIS). TOPSIS adalah didasarkan pada suatu konsep, dimana alternatif terpilih yang baik tidak hanya memiliki jarak terpendek dari solusi ideal positif tetapi juga memiliki jarak terpanjang dari solusi ideal negatif. Konsepnya sederhana dan mudah dipahami, komputasinya efisien, dan memiliki kemampuan untuk mengukur kinerja relatif dari alternatif-alternatif keputusan dalam bentuk matematis yang sederhana.

\section{ISI PENELITIAN}

\subsection{Metodologi}

Sumber data yang digunakan diperoleh dari PT. Shell yang berlokasi di Jl. Sisingamangaraja No.15, Sudirejo I, Medan Kota Sumatera Utara 20216. Data yang diambil berupa data karyawan untuk tahun 2017. Penentuan dalampemberian bonus karyawan menggunakan metode TOPSIS yang memerlukan beberapa kriteria seperti absen, perilaku, prestasi dan kerjasama tim.

Dalam hal ini, tujuan penelitian dilakukan untuk membantu perusahaan dalam menentukan karyawan yang berhak mendapatkan bonus tahunan karyawan, berdasarkan kriteria yang telah ditentukan. Prosedur dalam penentuan bonus karyawan dilakukan sebelum pada perusahaan tersebut menggunakan beberapa tahan, seperti staff administrasi membuat data absensi yang dilakukan secara rutin setiap hari; kemudian staff administrasi melakukan perekapan data absensi perbulan dan dilakukan perekapan selama satu tahun; staff administrasi menyerahkan hasil rekapan data absensi kepada Human Resource Develoment (HRD) untuk dilakukan pemeriksaan terhadap data absensi; HRD menerima dan memeriksa hasil rekapan data absensi yang telah diterima dari staff administrasi; HRD 
melakukan penilaian karyawan berdasarkan kriteria yang terdapat dalam form penilaian karyawan, kemudian hasil penilaian karyawan diserahkan kepada bagian administrasi untuk dilakukan perekapan; staff administrasi melakukan perekapan hasil penilaian karyawan yang diterima dari HRD; setelah itu staff administrasi membuat laporan penilaian karyawan, kemudian menyerahkan laporan penilaian karyawan tersebut kepada HRD; HRD menerima laporan penilaian karyawan; kemudian HRD melakukan perhitungan terhadap laporan absensi dan penilaian karyawan, serta membuat laporan perhitungan lalu diserahkan kepada general manajer untuk dilakukan pemeriksaan; setelah general manajer memeriksa laporan perhitungan, kemudian laporan perhitungan tersebut dilaporkan kepada Direktur Utama untuk meminta persetujuan; direktur utama memberikan memeriksa dan persetujuan atas laporan perhitungan, lalu diserahkan kepada HRD untuk melakukan pemberian bonus; hrd melakukan pemberian bonus tahunan.

Sedangkan activity diagram sistem yang sedang berjalan dapat dilihat pada Gambar 1

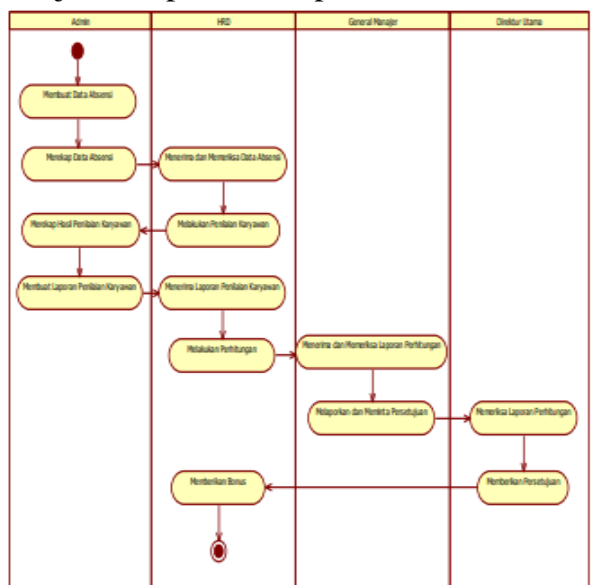

Gambar 1. Activity Diagram Sistem yang Berjalan

Berdasarkan permasalahan yang terjadi pada proses tahapan yang dilakukan sebelum dalam menentukan bonus karyawan pada perusahaan tersebut sangat membutuhkan waktu yang lama dan menimbulkan beberapa keluhan dari karyawan perusahaan, dikarenakan tidak meratanya pemberian bonus. Untuk itu dilakukan suatu pengembangan yang dapat membantu dalam proses penentuan bonus karyawan dengan menggunakan sistem aplikasi pada perusahaan tersebut. Dimana pengembangan sistem tersebut dilakukan dengan beberapa tahapan seperti pada alternatif pertama, penulis akan merancang sebuah sistem terkomputerisasi dimana data karyawan, datakriteria, dan perhitungan bonus akan diolah secara otomatis;pada alternatif kedua, penulis akan merancang sebuah sistem berbasis database agar mempermudah dalam pengaksesan. Proses penginputan data karyawan akan masuk pada sistem database dan kriteria yang diberikan akan dijadikan acuan serta dibuat perhitungannya menggunakan metode TOPSIS sehingga dapat digunakan untuk menentukan karyawan yang berhak mendapatkan bonus tahunan.

Sedangkan metode yang digunakan dalam pengembangan aplikasi pemberian bonus karyawan adalah metode TOPSIS.TOPSIS (Technique For Orders Reference by Similarity to Ideal Solution) adalah salah satu metode pengambilan keputusan multi kriteria yang pertama kali diperkenalkan oleh Yoon dan Hwang, 1981. Metode ini menggunakan prinsip bahwa alternatif yang terpilih harus mempunyai jarak terdekat dari solusi ideal positif dan terjauh dari solusi ideal negatif. Pilihan akan diurutkan berdasarkan nilai sehingga alternatif yang memiliki jarak terpendek dengan solusi ideal positif adalah alternatif yang terbaik. Solusi ideal positif didefinisikan sebagai jumlah dari seluruh nilai terbaik yang dapat dicapai pada setiap atribut, sedangkan solusi ideal negative terdiri dari seluruh nilai terburuk yang dicapai setiap atribut, TOPSIS mempertimbangkan keduanya, jarak terhadap solusi ideal positif dan jarak terhadap solusi ideal negative dengan mengambil kedekatan relative terhadap solusi ideal positif [2].

Metode ini banyak digunakan untuk menyelesaikan pengambilan keputusan secara praktis. Hal ini disebabkan konsepnya sederhana dan mudah dipahami, komputasinya efisien, dan memiliki kemampuan mengukur kinerja relatif dari alternatif-alternatif keputusan.

Metode pengembangan sistem yang digunakan adalah sistem Rational Unified Process (RUP) merupakan suatu metode rekayasa perangkat lunak yang dikembangkan dengan mengumpulkan berbagai best practises yang terdapat dalam industri pengembangan perangkat lunak. Ciri utama metode ini adalah menggunakan use-case driven dan pendekatan iteratif untuk siklus pengembangan perankat lunak. RUP menggunakan konsep object oriented, dengan aktivitas yang berfokus pada pengembangan model dengan menggunakan Unified Modeling Language (UML), melalui Gambar 2dapat dilihat bahwa RUP memiliki, dimensi pertama digambarkan secara horizontal, dan dimensi kedua digambarkan secara vertikal. 


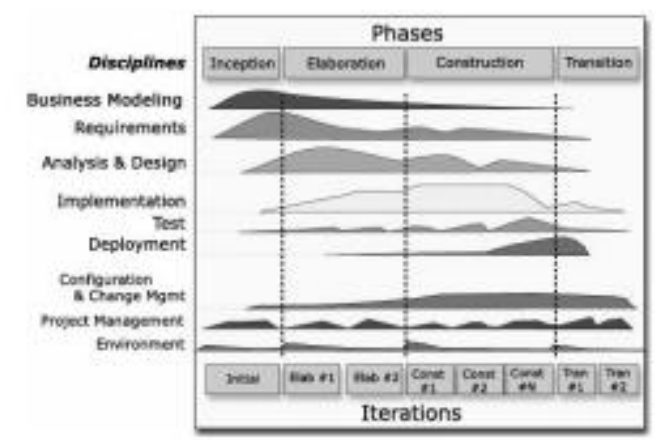

Gambar 2.Arsitektur Rational Unified Process

(RUP)

Sedangkan dalam pengembangan perangkat lunak sistem pendukung keputusan ini, digunakan tools Unified Modelling Language 2.0 (UML). UML adalah sebuah bahasa yang telah menjadi standar dalam industri untuk visualisasi, merancang dan mendokumentasikan sistem piranti lunak. UML menawarkan sebuah standar untuk merancang model sebuah system. Sedangkan konsepsi dasar UML 2.0 yang akan digunakan dalam pengembangan sistem itu sendiri antara lain: (1) Use Case Diagram. (2). Class Diagram. (3). Activity Diagram. (4). Sequence Diagram.

\subsection{Hasil dan Pembahasan}

\subsubsection{Analisis Sistem}

Sistem pendukung keputusan pemberian bonus tahunan karyawan menggunakan metode TOPSIS akan ditentukan dengan beberapa tahapan. Tahapantahapan tersebut meliputi:

1. Menentukan kriteria-kriteria yang akan dijadikan acuan dalam pengambilan keputusan dan memberikan bobot penilaian untuk setiap kriteria.Sebagai contoh kasus perhitungan, penulis mengambil contoh kasus 5 (lima) orang karyawan.

A1 = Alamsyah, A2 = Irwan, A3 = Imam Syahputra, A4 = Handoko, A5 = Susanto. [4]

Berdasarkan observasi, data yang diperoleh didapatkan input kriteria sebagai berikut:

Tabel 1. Kriteria Pemberian Bonus Karyawan

\begin{tabular}{|c|c|c|c|c|}
\hline $\begin{array}{c}\text { Ko } \\
\text { de }\end{array}$ & Kriteria & $\begin{array}{c}\text { Rati } \\
\text { ng }\end{array}$ & $\begin{array}{c}\text { Sub } \\
\text { Kriteria }\end{array}$ & Nilai \\
\hline C1 & Absensi & 5 & $\begin{array}{c}\text { SangatBai } \\
\text { k }\end{array}$ & $\begin{array}{c}241- \\
303\end{array}$ \\
\cline { 3 - 5 } & & 4 & Baik & $\begin{array}{c}181- \\
240\end{array}$ \\
\cline { 3 - 5 } & & 3 & Cukup & $\begin{array}{c}121- \\
180\end{array}$ \\
\cline { 3 - 5 } & & 2 & Kurang & $\begin{array}{c}61- \\
120\end{array}$ \\
\cline { 3 - 5 } & & 1 & SangatKur & $1-60$ \\
& & & ang & \\
\hline C2 & PenilaianKary & 5 & SangatBai & $75-80$ \\
& awan & & k & \\
\cline { 3 - 5 } & & 4 & Baik & $55-74$ \\
\cline { 3 - 5 } & & 3 & Cukup & $25-54$ \\
\hline
\end{tabular}

\begin{tabular}{|c|c|c|c|c|}
\hline & & 2 & Kurang & $5-24$ \\
\hline & & 1 & $\begin{array}{c}\text { SangatKur } \\
\text { ang }\end{array}$ & $0-4$ \\
\hline \multirow[t]{5}{*}{$\mathrm{C} 3$} & \multirow[t]{5}{*}{ MasaKerja } & 5 & $\begin{array}{c}\text { SangatBai } \\
k\end{array}$ & $\begin{array}{c}>10 \\
\text { Tahun }\end{array}$ \\
\hline & & 4 & Baik & $\begin{array}{c}>5 \\
\text { Tahun }\end{array}$ \\
\hline & & 3 & Cukup & $\begin{array}{c}>3 \text { Tah } \\
\text { un }\end{array}$ \\
\hline & & 2 & Kurang & $\begin{array}{c}>1 \\
\text { Tahun }\end{array}$ \\
\hline & & 1 & $\begin{array}{c}\text { SangatKur } \\
\text { ang }\end{array}$ & $\begin{array}{c}<1 \\
\text { tahun }\end{array}$ \\
\hline \multirow[t]{5}{*}{4} & \multirow[t]{5}{*}{ Loyalitas } & 5 & $\begin{array}{c}\text { SangatBai } \\
k\end{array}$ & $\begin{array}{l}95- \\
100\end{array}$ \\
\hline & & 4 & Baik & $85-94$ \\
\hline & & 3 & Cukup & $75-84$ \\
\hline & & 2 & Kurang & $65-74$ \\
\hline & & 1 & $\begin{array}{l}\text { SangatKur } \\
\text { ang }\end{array}$ & $0-64$ \\
\hline
\end{tabular}

Tabel 2. Rating Kecocokan

\begin{tabular}{|c|c|}
\hline Rating & Keterangan \\
\hline 5 & SangatBaik \\
\hline 4 & Baik \\
\hline 3 & Cukup \\
\hline 2 & Kurang \\
\hline 1 & SangatKurang \\
\hline \multicolumn{2}{|c|}{ Tabel 3. Bobot Preferensi } \\
\hline
\end{tabular}

\begin{tabular}{|c|c|c|}
\hline Kode & Kriteria & Bobot (W) \\
\hline C1 & Absensi & 0,372 \\
\hline C2 & PenilaianKaryawan & 0,284 \\
\hline C3 & MasaKerja & 0,070 \\
\hline C4 & Loyalitas & 0,274 \\
\hline
\end{tabular}

2. Menyusun Matriks Keputusan

Dari Setiap Alternatif Matriks keputusan berikut diperoleh dari data yang terdapat di PT Shell Medan.

Tabel 4. Matriks Keputusan Setiap Alternatif

\begin{tabular}{|l|c|c|c|c|}
\hline $\begin{array}{c}\text { Altern } \\
\text { atif }\end{array}$ & $\begin{array}{c}\text { Abse } \\
\text { nsi }\end{array}$ & $\begin{array}{c}\text { PenilaianKa } \\
\text { ryawan }\end{array}$ & $\begin{array}{c}\text { Masa } \\
\text { Kerja }\end{array}$ & $\begin{array}{c}\text { Loyal } \\
\text { itas }\end{array}$ \\
\hline $\begin{array}{l}\text { Alams } \\
\text { yah }\end{array}$ & 305 & 67 & 4 & 85 \\
\hline Irwan & 311 & 41 & 10 & 83 \\
\hline $\begin{array}{l}\text { Imam } \\
\text { Syahp } \\
\text { utra }\end{array}$ & 306 & 61 & 3 & 95 \\
\hline $\begin{array}{l}\text { Hand } \\
\text { oko }\end{array}$ & 312 & 54 & 9 & 88 \\
\hline $\begin{array}{l}\text { Susan } \\
\text { to }\end{array}$ & 310 & 46 & 8 & 80 \\
\hline
\end{tabular}

3. Menentukan Matriks Keputusan Ternormalisasi Matriks keputusan yang telah disusun kemudian dinormalisasikan agar masing-masing data nilai dari setiap kriteria memiliki panjang yang sama. Matriks keputusan dinormalisasikan dengan rumus berikut:

Keterangan :

$\mathrm{i}=1,2, \ldots . ., \mathrm{m}$ 
$\mathrm{j}=1,2, \ldots ., \mathrm{n}$

Perhitungan :

a. Untuk kriteria Absensi (C1)

$$
\begin{aligned}
\begin{aligned}
|\mathrm{C} 1| & =\sqrt{305^{2}+311^{2}+306^{2}} \\
& =\sqrt{93.025+96.721+93.636} \\
& =\sqrt{476.826}
\end{aligned} \\
=\underline{\underline{9}+310^{2}, 526} \\
|R 11|=\frac{X 11}{|C 1|}=\frac{305}{690,526}=0,442 \\
|R 21|=\frac{X 21}{|C 1|}=\frac{311}{690,526}=0,450 \\
|R 31|=\frac{X 31}{|C 1|}=\frac{306}{690,526}=0,443 \\
|R 41|=\frac{X 41}{|C 1|}=\frac{312}{690,526}=0,452 \\
|R 51|=\frac{X 51}{|C 1|}=\frac{310}{690,526}=0,449
\end{aligned}
$$

b. Untuk kriteria Penilaian Karyawan (C2)

$$
\begin{aligned}
& |C 2|=\sqrt{67^{2}+41^{2}+61^{2}+54^{2}+46^{2}} \\
& =\sqrt{\begin{array}{l}
4.489+1.681+3,271+2,916 \\
+2.116
\end{array}} \\
& =\sqrt{14.923} \\
& =122,160 \\
& |R 12|=\frac{X 12}{|C 2|}=\frac{67}{122,160}=0,548 \\
& |R 22|=\frac{X 22}{|C 2|}=\frac{41}{122,160}=0,336 \\
& |R 32|=\frac{X 32}{|C 2|}=\frac{61}{122,160}=0,499 \\
& |R 42|=\frac{X 42}{|C 2|}=\frac{54}{122,160}=0,442 \\
& |R 52|=\frac{X 52}{|C 2|}=\frac{46}{122,160}=0,376
\end{aligned}
$$

c. Untuk kriteria masa kerja (C3)

$$
\begin{aligned}
|C 3| & =\sqrt{4^{2}+10^{2}+3^{2}+9^{2}+8^{2}} \\
& =\sqrt{16+100+9+81+64} \\
& =\sqrt{270} \\
& =\underline{\underline{16,432}} \\
|R 13| & =\frac{X 13}{|C 3|}=\frac{4}{16,432}=0,243 \\
|R 23| & =\frac{X 23}{|C 3|}=\frac{10}{16,432}=0,608 \\
|R 13| & =\frac{X 13}{|C 3|}=\frac{4}{16,432}=0,243 \\
|R 33| & =\frac{X 33}{|C 3|}=\frac{3}{16,432}=0,182 \\
|R 43| & =\frac{X 43}{|C 3|}=\frac{9}{16,432}=0,548
\end{aligned}
$$

$$
|R 53|=\frac{X 53}{|C 3|}=\frac{8}{16,432}=0,487
$$

d. Untuk kriteria loyalitas (C4)

$$
\begin{aligned}
|C 4| & =\sqrt{85^{2}+83^{2}+95^{2}+88^{2}+80^{2}} \\
& =\sqrt{\begin{array}{l}
7.225+6.889+9,025 \\
+7.744+6.400
\end{array}} \\
& =\sqrt{37.283} \\
& =193,088 \\
R 14 & =\frac{X 14}{|C 4|}=\frac{85}{193,088}=0,440 \\
R 24 & =\frac{X 24}{|C 4|}=\frac{83}{193,088}=0,430 \\
R 34 & =\frac{X 34}{|C 4|}=\frac{95}{193,088}=0,492 \\
R 44 & =\frac{X 44}{|C 4|}=\frac{88}{193,088}=0,456 \\
R 54 & =\frac{X 54}{|C 4|}=\frac{80}{193,088}=0,414
\end{aligned}
$$

4. Menentukan Matriks Keputusan Normalisasi Terbobot

Matriks keputusan ternormalisasi terbobot diperoleh dengan cara mengalikan setiap kolom elemen matriks keputusan ternormalisasi dengan bobot preferensi setiap kriteria yaitu W $=(0,372,0,284,0,070,0,274)$.[6]

a. Untuk kriteria absensi (C1)

$$
\begin{aligned}
& Y 11=0,442 \times 0,372=0,164 \\
& Y 21=0,450 \times 0,372=0,167 \\
& Y 31=0,443 \times 0,372=0,165 \\
& Y 41=0,452 \times 0,372=0,168 \\
& Y 51=0,449 \times 0,372=0,167
\end{aligned}
$$

b. Untuk kriteria penilaian karyawan absensi (C2)

$$
\begin{aligned}
& Y 12=0,548 \times 0,284=0,156 \\
& Y 22=0,336 \times 0,284=0,095 \\
& Y 32=0,499 \times 0,284=0,142 \\
& Y 42=0,442 \times 0,284=0,125 \\
& Y 52=0,376 \times 0,284=0,107
\end{aligned}
$$

c. Untuk kriteria masa kerja (C3)

$$
\begin{gathered}
Y 13=0,243 \times 0,0,070=0,017 \\
Y 23=0,68 \times 0,0,070=0,042 \\
Y 33=0,182 \times 0,0,070=0,013 \\
Y 43=0,548 \times 0,0,070=0,038 \\
Y 53=0,487 \times 0,0,070=0,034 \\
\text { d. Untuk kriteria loyalitas }(\mathrm{C} 4) \\
Y 14=0,440 \times 0,274=0,120 \\
Y 24=0,430 \times 0,274=0,118 \\
Y 34=0,492 \times 0,274=0,135 \\
Y 44=0,456 \times 0,274=0,125 \\
Y 54=0,414 \times 0,274=0,113
\end{gathered}
$$

5. Menentukan Solusi Ideal Positif

$Y_{1}^{+}=\max \{0,164 ; 0,167 ; 0,165 ; 0,168 ; 0,167\}$

$=0,168$

$Y_{2}^{+}=\max \{0,156 ; 0,095 ; 0,142 ; 0,125 ; 0,107\}$

$=0,156$ 
$Y_{3}^{+}=\max \{0,017 ; 0,042 ; 0,013 ; 0,038 ; 0,034\}$

$=0,042$

$Y_{4}^{+}=\max \{0,120 ; 0,118 ; 0,135 ; 0,125 ; 0,113\}$

$=0,135$

$A^{+}=\{0,168 ; 0,156 ; 0,042 ; 0,135\}$

6. Menentukan Solusi Ideal Negatif[7]

$Y_{1}^{-}=\min \{0,164 ; 0,167 ; 0,165 ; 0,168 ; 0,167\}$

$=0,164$

$Y_{2}^{-}=\min \{0,156 ; 0,095 ; 0,142 ; 0,125 ; 0,107\}$

$=0,095$

$Y_{3}^{-}=\min \{0,017 ; 0,042 ; 0,013 ; 0,038 ; 0,034\}$

$=0,013$

$Y_{4}^{-}=\min \{0,120 ; 0,118 ; 0,135 ; 0,125 ; 0,113\}$

$=0,113$

$A-=\{0,164 ; 0,095 ; 0,013 ; 0,113\}$

7. Menghitung Jarak Alternatif dengan Solusi Ideal Positif [8]

Jarak pendekatan terhadap solusi ideal positif diperoleh dengan rumus:

$$
D_{i}^{+}=\sqrt{\sum_{j=1}^{n}\left(Y i^{+}-Y i j\right)^{2}}
$$

Keterangan :

$\mathrm{i}=1,2, \ldots ., \mathrm{m}$

Perhitungan:

$$
\begin{aligned}
D_{1}^{+} & =\sqrt{\begin{array}{l}
(0,168-0,164)^{2}+ \\
(0,156-0,156)^{2}+ \\
(0,042-0,017)^{2}+ \\
(0,135-0,120)^{2}
\end{array}} \\
& =\sqrt{\begin{array}{l}
(0,004)^{2}+(0)^{2}+ \\
(0,025)^{2}+(0,015)^{2}
\end{array}} \\
& =\sqrt{\begin{array}{l}
0,000016+0+ \\
0,000625+0,000225
\end{array}} \\
& =\sqrt{0,0009=0,03} \\
D_{2}^{+} & =\sqrt{\begin{array}{l}
(0,168-0,167)^{2} \\
+(0,156-0,095)^{2} \\
+(0,042-0,042)^{2}
\end{array}} \\
& =\sqrt{(0,001)^{2}+(0,061)^{2}+(0)^{2}+(0,017)^{2}} \\
= & \sqrt{0,000001+0,003721+0+0,000289} \\
= & \sqrt{0,004=0,06}
\end{aligned}
$$

$$
\begin{aligned}
& D_{3}^{+}=\sqrt{\begin{array}{l}
(0,168-0,165)^{2} \\
+(0,156-0,142)^{2} \\
+(0,042-0,013)^{2} \\
+(0,135-0,135)^{2}
\end{array}} \\
& =\sqrt{\begin{array}{l}
(0,003)^{2}+(0,014)^{2} \\
+(0,029)^{2}+(0)^{2}
\end{array}} \\
& =\sqrt{\begin{array}{l}
0,000009+0,000196 \\
+0,000841+0
\end{array}} \\
& =\frac{\sqrt{0,0 O 1}=0,03 z}{\sqrt{(0,168-0,168)^{2}}}
\end{aligned}
$$

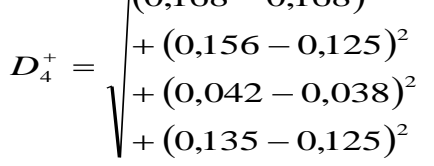

$$
\begin{aligned}
& =\sqrt{\begin{array}{l}
(0)^{2}+(0,031)^{2}+(0,004)^{2} \\
+(0,029)^{2}
\end{array}} \\
& =\sqrt{0+0,000961+0,000016+0,0001} \\
& =\sqrt{0,001}=0,03 \\
& D_{5}^{+}=\sqrt{\begin{array}{l}
(0,167-0,168)^{2} \\
+(0,156-0,107)^{2} \\
+(0,042-0,034)^{2} \\
+(0,135-0,113)^{2}
\end{array}} \\
& =\sqrt{\begin{array}{l}
(0,001)^{2}+(0,049)^{2} \\
+(0,008)^{2}+(0,022)^{2}
\end{array}} \\
& =\sqrt{\begin{array}{l}
0,000001+0,002401 \\
+0,000064+0,000484
\end{array}} \\
& =\sqrt{\mathrm{O,003}}=0,05
\end{aligned}
$$

8. Menghitung Jarak Alternatif dengan Solusi Ideal Negatif

Jarak pendekatan terhadap solusi ideal negatif diperoleh dengan rumus:

$$
D_{i}^{-}=\sqrt{\sum_{j=1}^{n}\left(Y i j-Y i^{-}\right)^{2}}
$$

Keterangan :

$\mathrm{i}=1,2, \ldots ., \mathrm{m}$

Perhitungan:

$$
\begin{aligned}
D_{1}^{-} & =\sqrt{\begin{array}{l}
(0,164-0,164)^{2} \\
+(0,156-0,095)^{2} \\
+(0,017-0,013)^{2} \\
+(0,120-0,113)^{2}
\end{array}} \\
= & \sqrt{\begin{array}{l}
(0)^{2}+(0,061)^{2} \\
+(0,004)^{2}+(0,007)^{2}
\end{array}} \\
= & \sqrt{\begin{array}{l}
0+0,003721+0,000016 \\
+0,000049
\end{array}} \\
= & \sqrt{0,0038}=0,06
\end{aligned}
$$




$$
\begin{aligned}
D_{2}^{-} & =\sqrt{\begin{array}{l}
(0,167-0,164)^{2} \\
+(0,095-0,095)^{2} \\
+(0,042-0,013)^{2} \\
+(0,118-0,113)^{2}
\end{array}} \\
& =\sqrt{(0,003)^{2}+(0)^{2}+(0,029)^{2}+(0,005)^{2}} \\
& =\sqrt{0,000009+0+0,000841+0,000025} \\
& =\sqrt{0,0009}=0,03 \\
D_{3}^{-} & =\sqrt{\begin{array}{l}
(0,165-0,164)^{2}+(0,142-0,095)^{2} \\
+(0,013-0,013)^{2}+(0,135-0,113)^{2}
\end{array}} \\
& =\sqrt{(0,001)^{2}+(0,047)^{2}+(0)^{2}+(0,022)^{2}} \\
& =\sqrt{0,000001+0,002209+0+0,000484} \\
& =\sqrt{0,0027}=0,05
\end{aligned}
$$

$$
\begin{aligned}
D_{4}^{-} & =\sqrt{\begin{array}{l}
(0,168-0,164)^{2}+(0,125-0,095)^{2} \\
+(0,038-0,013)^{2}+(0,125-0,113)^{2}
\end{array}} \\
& =\sqrt{(0,0004)^{2}+(0,030)^{2}+(0,025)^{2}+(0,012)^{2}} \\
& =\sqrt{\begin{array}{l}
0,000016+0,000900+0,000625 \\
+0,000144
\end{array}} \\
& =\sqrt{0,0017}=0,04
\end{aligned}
$$

$$
\begin{aligned}
D_{5}^{-} & =\sqrt{\begin{array}{l}
(0,167-0,164)^{2} \\
+(0,107-0,095)^{2} \\
+(0,034-0,013)^{2} \\
+(0,113-0,113)^{2}
\end{array}} \\
& =\sqrt{(0,003)^{2}+(0,012)^{2}+(0,021)^{2}+(0)^{2}} \\
& =\sqrt{0,000009+0,000144+0,000441+0} \\
& =\sqrt{0,006}=0,02
\end{aligned}
$$$$
V_{5}(A 5)=\frac{0,02}{0,02+0,05}=\frac{0,02}{0,07}=0,2857
$$

Hasil perhitungan nilai preferensi untuk setiap alternatif dapat dilihat pada Tabel 3.5.

Tabel 5. Nilai Preferensi untuk Setiap Alternatif

\begin{tabular}{|l|c|}
\hline \multicolumn{1}{|c|}{ Alternatif } & NilaiPreferensi \\
\hline A1 (Alamsyah) & 0,6667 \\
\hline A2 (Irwan) & 0,3333 \\
\hline A3 (Imam Syahputra) & 0,6250 \\
\hline A4 (Handoko) & 0,5714 \\
\hline A5 (Susanto) & 0,2857 \\
\hline
\end{tabular}

10. Merangking Setiap Alternatif

Hasil perankingan didasarkan pada nilai tertinggi ke terendah, sebagaimana dapat dilihat pada tabel 6 :

Tabel 6. RankingAlternatif

\begin{tabular}{|l|c|c|}
\hline \multicolumn{1}{|c|}{ Alternatif } & $\begin{array}{c}\text { Nilai } \\
\text { Preferensi }\end{array}$ & Ranking \\
\hline A1 (Alamsyah) & 0,6667 & 1 \\
\hline A2 (Irwan) & 0,3333 & 4 \\
\hline $\begin{array}{l}\text { A3(Imam } \\
\text { Syahputra) }\end{array}$ & 0,6250 & 2 \\
\hline A4 (Handoko) & 0,5714 & 3 \\
\hline A5 (Susanto) & 0,2857 & 5 \\
\hline
\end{tabular}

Sedangkan perhitungan persentase nilai preferensi dapat dilihat sebagai berikut :

$$
\begin{aligned}
& \text { A1 }=0,6667 \times 100 \%=66,67 \% \\
& \text { A2 }=0,3333 \times 100 \%=33,33 \% \\
& \text { A3 }=0,6250 \times 100 \%=62,50 \% \\
& \text { A4 }=0,5714 \times 100 \%=57,14 \% \\
& \text { A5 }=0,2857 \times 100 \%=28,57 \%
\end{aligned}
$$

Keterangan :

$\mathrm{i}=1,2, \ldots ., \mathrm{m}$

Perhitungan :

$$
\begin{aligned}
& V_{1}(A 1)=\frac{0,06}{0,06+0,03}=\frac{0,06}{0,09}=0,6667 \\
& V_{2}(A 2)=\frac{0,03}{0,03+0,06}=\frac{0,03}{0,09}=0,3333 \\
& V_{3}(A 3)=\frac{0,05}{0,05+0,03}=\frac{0,05}{0,08}=0,6250 \\
& V_{4}(A 4)=\frac{0,04}{0,04+0,03}=\frac{0,04}{0,07}=0,5714
\end{aligned}
$$




\subsection{Implementasi Sistem}

Tampilan hasil implementasi pemberian bonus karyawan dengan metode TOPSIS dapat dilihat sebagai berikut :

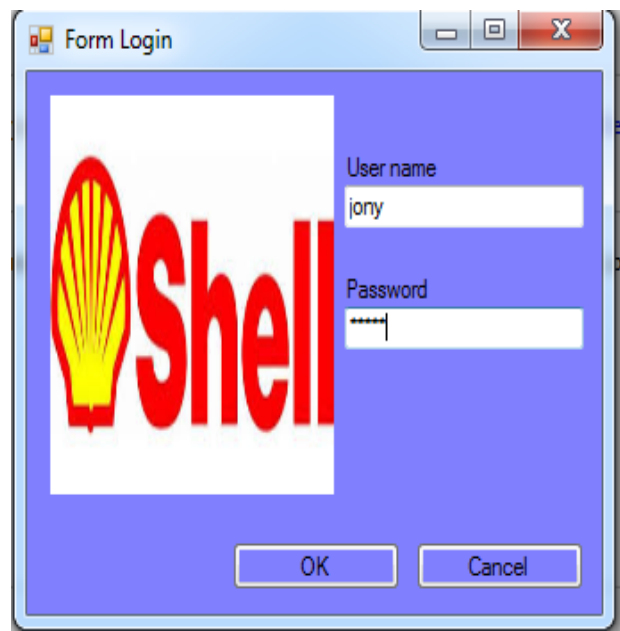

Gambar 3. Tampilan Form Login

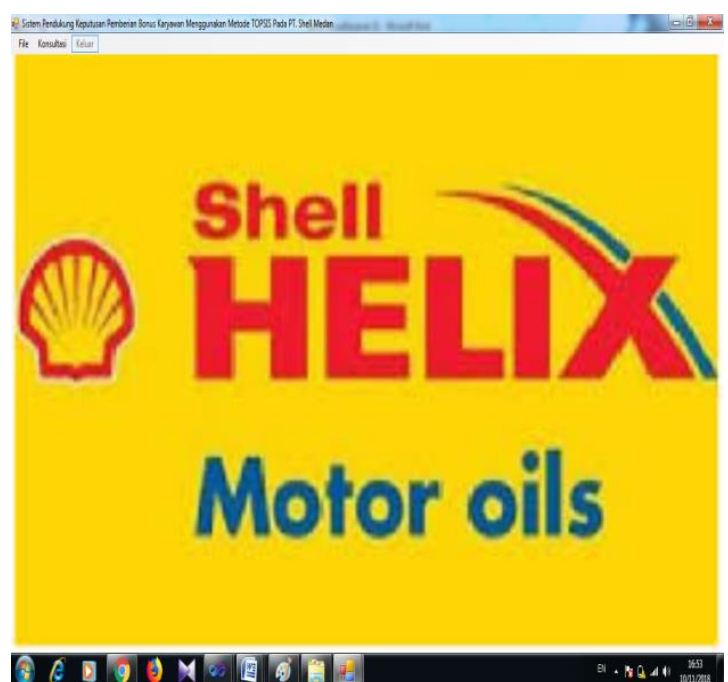

Gambar 4. Tampilan Form Menu Utama

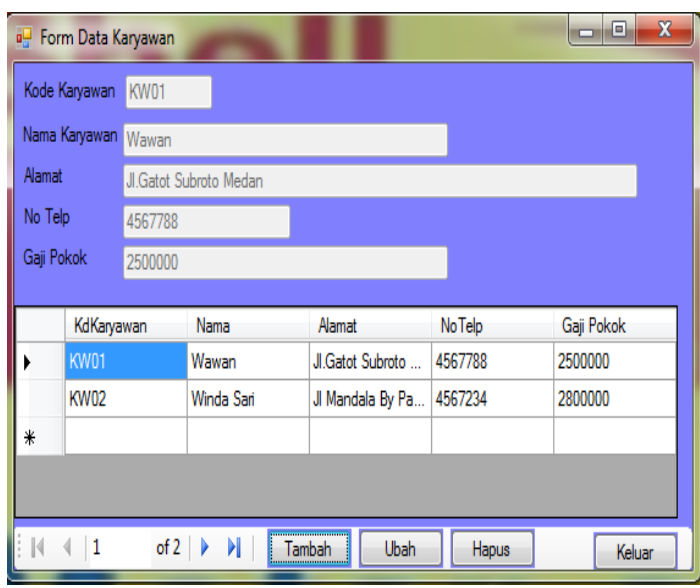

Gambar 5. Tampilan Form Karyawan

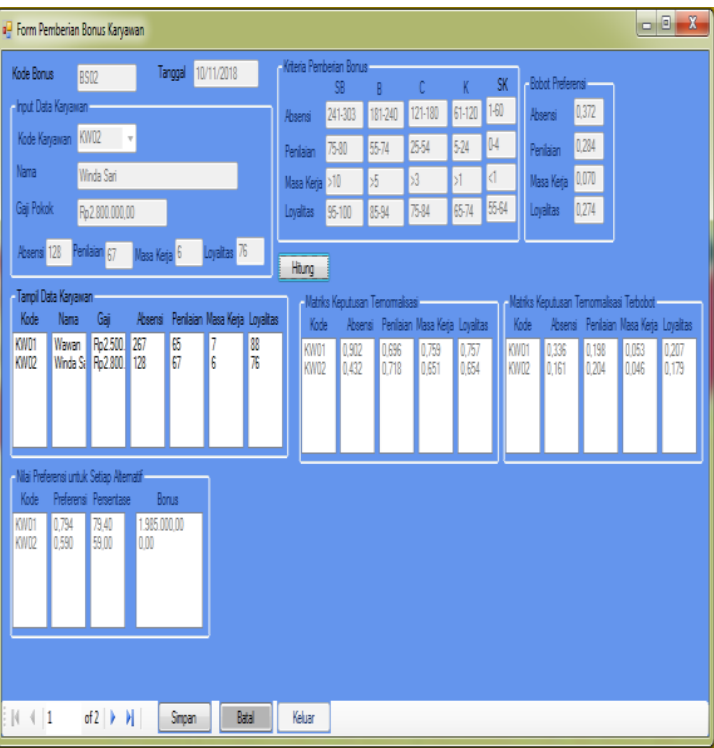

Gambar 6. Tampilan Form Konsultasi

\section{KESIMPULAN}

Berdasarkan hasil penelitian yang dilakukan pada PT. Shell Medan, maka peneliti menarik kesimpulan bahwa kriteria yang menjadi prioritas untuk menentukan karyawan yang berhak mendapatkan bonus tahunan adalah kriteria absensi dengan bobot sebesar 0,372 $(32,7 \%)$. Nilai preferensi terbesar diperoleh karyawan yang bernama Alamsyah dengan nilai sebesar 0,6667 (66,67\%), kemudian diikuti Imam Syahputra dengan nilai 0,6250 (62,50\%), Handoko dengan nilai 0,5714 (57,14\%), Irwan dengan nilai $0,3333(33,33 \%)$ dan Susanto dengan nilai $0,2857 \quad(28,57 \%)$. Hasil implementasi tersebut menunjukkan bahwa metode TOPSIS (Technique For Order Preference By Similarity to Ideal Solution) dapat memudahkan pihak perusahaan/manajemen terutama HRD dalam menentukan karyawan yang berhak mendapatkan bonus tahunan secara tepat dan akurat berdasarkan kriteria yang ditentukan.

\section{PENUTUP}

Dengan di bangunnya suatu sistem informasi dalam penentuan pemberian bonus karyawan yang dirancang menggunakan metode TOPSIS Ini dapat menyelesaikan segala masalah 
yang muncul sebelumnya. Bedasarkan kesimpulan di atas maka yang dapat di kemukakan agar menjadi bahan masukan dan pertimbangan sistem informasi penentuan pemberian bonus karyawan. Adapun saran-saran yang di kemukakan untuk mengembangkan sistem ini jauh lebih baik, di antaranya ada sebagai berikut :

1. bahwa kriteria yang menjadi prioritas untuk menentukan karyawan yang berhak mendapatkan bonus tahunan

2. memudahkan pihak perusahaan/manajemen terutama HRD dalam menetukan karyawan yang berhak mendapatatkan bonus tahunan secara tepat dan akurat berdasarkan kriteria yang di tentukan oleh perusahaan

\section{UCAPAN TERIMA KASIH}

Penulis mengucapkan terima kasih kepada PT Shell Medan, Universitas Prima Indonesia Medan, Dosen Pembimbing, yang telah memberikan kesempatan dan dukungan sehingga penelitian ini dapat terselesaikan dengan baik.

\section{DAFTAR PUSTAKA}

[1] Darsono Nababan dan Robbi Rahim, "Sistem Pendukung Keputusan Reward Bonus Karyawan dengan Metode TOPSIS", Jurnal ISD Vol.3 No.1 Januari-Juni 2018 pISSN:2477-863X eISSN:2528-5114.

[2] Nurjaya dan Vera Musyafiroh, "Pemilihan Salesman Terbaik Menggunakan Metode TOPSIS", Prosiding Seminar Nasional Informatika dan Sistem Informasi ISSN 2549-4805, 2017.

[3] Sriani, "analisa sistem pendukung keputusan menggunakan metode TOPSIS untuk sistem penerimaan pegawai pada sma al washliyah tanjung morawa", Jurnal Ilmu Komputer dan Informatika Volume: 02, Number : 01, April 2018 ISSN 2598-6341.

[4] Rachmat Agusli , Muhammad Iqbal Dzulhaq , Uswatun Khasanah, " Sistem Pendukung Keputusan Pemberian Bonus Tahunan Karyawan Menggunakan Metode TOPSIS", JURNAL Sisfotek Global ISSN : 2088 1762 Vol. 7 No. 2, September 2017.

[5] Fisabilillah, Dyah Ayu Irawati, "Sistem Pendukung Keputusan Pemberian Bonus Tahunan Pada Karyawan Dengan Metode FuzzyUZZY-TOPSIS", Prosiding Seminar Informatika Aplikatif Polinema 2015 (SIAP 2015) Prosiding Seminar Informatika Aplikatif Polinema 2015 (SIAP 2015)

[6] Halim Agung , Ricky, "Aplikasi Sistem Pendukung Keputusan Untuk Pemilihan Siswa Teladan Menggunakan Metode TOPSIS", JURNAL ILMIAH FIFO P-ISSN 2085-4315 / E-ISSN 2502-8332 Volume VIII/No. 2/November/2016
[7] Yanthi Charolina, "Sistem Pendukung Keputusan Untuk Menentukan Pemberian Bonus Tahunan Menggunakan Metode FUZZY LOGIC Tipe MAMDANI (Studi Kasus Pada Karyawan PT. Sunhope Indonesia Di Jakarta)", Jurnal Teknologi Informasi ISSN: 1979-1496 Volume 12, Nomor 2, Agustus 2016.

[8] Riza Chintya Dewi , Ely Setyo Astuti, "Sistem Pendukung Keputusan Pemberian Bonus Tahunan Pada Karyawan Dengan Metode WP", Prosiding Seminar Informatika Aplikatif Polinema 2015 ISSN: 2460-1160 (SIAP 2015).

[9] Triyana Widya Ningrum, Sherly Valentina, Dafid, " Analisis dan Perancangan Sistem Pendukung Keputusan Pemberian Bonus Tahunan Karyawan dengan Metode SAW pada PT. XYZ", Jatisi, ISSN PRINT : 24074322 ISSN ONLINE : 2503-2933 Vol. 3 No. 1 September 2016. 